\title{
MONITORING OF CRACK GROWTH IN A STRUCTURE UNDER A COMPOSITE PATCH
}

\author{
Michał Sałaciński \\ Piotr Synaszko \\ Michal Stefaniuk \\ Krzysztof Dragan \\ Air Force Institute of Technology, \\ Warsaw, Poland
}

\begin{abstract}
In civil as well as in military aviation, boron, carbon and aramid fiber reinforced composites are employed for the repair of metal structures. After such composite bonded repairs, the monitoring of the repaired structure along with the composite patch and its bond is necessary.

The paper describes the possibilities of utilizing NDT methods for periodical check-ups and examinations. Also, a novel approach to continuous monitoring of the repaired structure is presented.
\end{abstract}

\section{INTRODUCTION}

X-ray diffraction can be used as a non-destructive method to measure residual stress in Composite bonded repair of metal structures may be used after the aircraft suffers accidental damage. This includes the case of battle damage. Usually, such a repair is only temporary, and is shortly replaced by an extensive repair in a certified facility[1].

The use of modern adhesive films and composite materials, proper surface preparation, along with the use of high-grade heat cycle control instrumentation (to ensure the correct autoclave working conditions), guarantees a durable repair. The repair methods are verified through fatigue testing, and if deemed suitable, are subsequently included in maintenance and overhaul instructions [2,3].

In both cases, checks and quality control of the performed repair need to be carried out afterwards (in particular the patch's impregnation and its bond to the metal structure).

Even though the period of safe operation after a certified facility repair is strictly specified (determined in earlier tests), as a safety precaution, the damage tolerance approach is also employed, i.e. the structure's condition and crack growth under the patch are regularly monitored, as well as the patch itself $[5,6,7]$.

\section{The test specimens}

Four identical metal plate specimens were made (2024-T3 steel). The damage was modeled in the form of fatigue cracks of different sizes, initiated on holes in each of the specimens (fig 1). 
a)

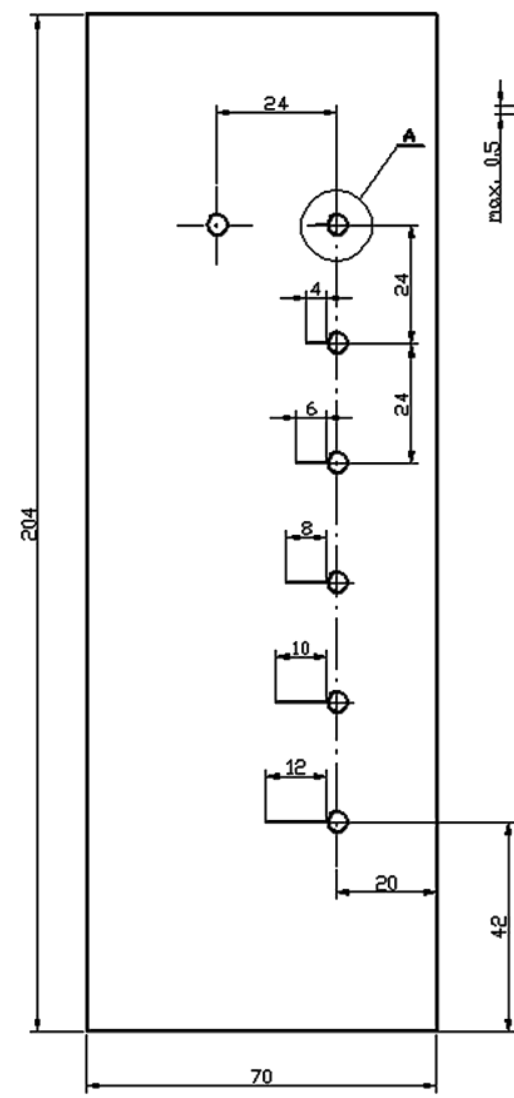

b)

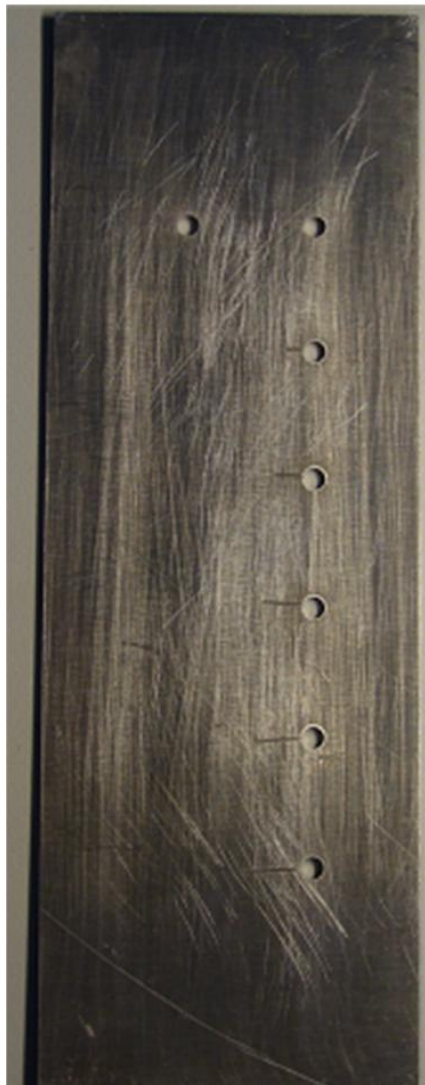

Fig. 1. Metal specimens with cracks modeled: a) crack model dimensions, b) actual specimens

In the AFIT laboratory, CBR was performed on three of the specimens with the use of Carbon (CFRP), Aramide (ARFP) and Boron (bfrP) fiber reinforced polymer patches.

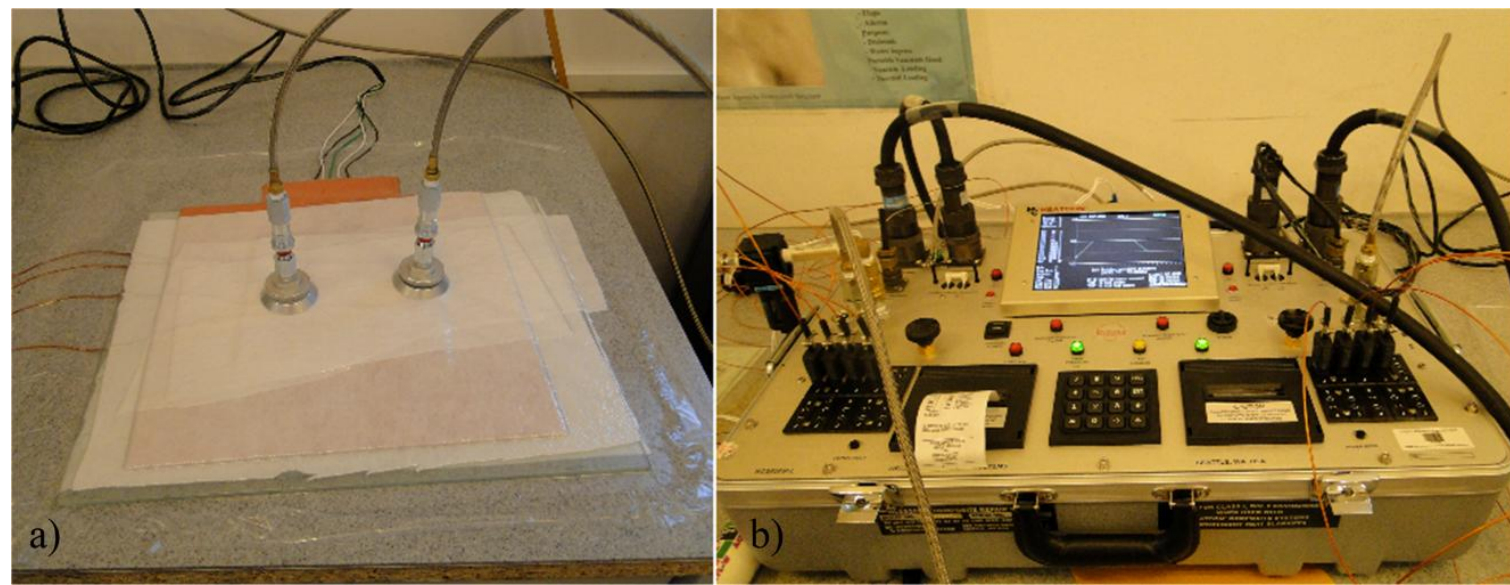

Fig. 2. Cure cycle by hot bonder: a) vacuum bag with hot bonder, b) control unit

The test repairs were performed using prepreg materials, in accordance to existing standards [5-7]. Metal specimens' surface was degreased, sandblasted and subsequently covered by anticorrosion and adhesion-improving compound. The composite patch was bonded to the repaired structure using an adhesive epoxy film. The repair operation was performed in a single step (using a single heat cycle). 

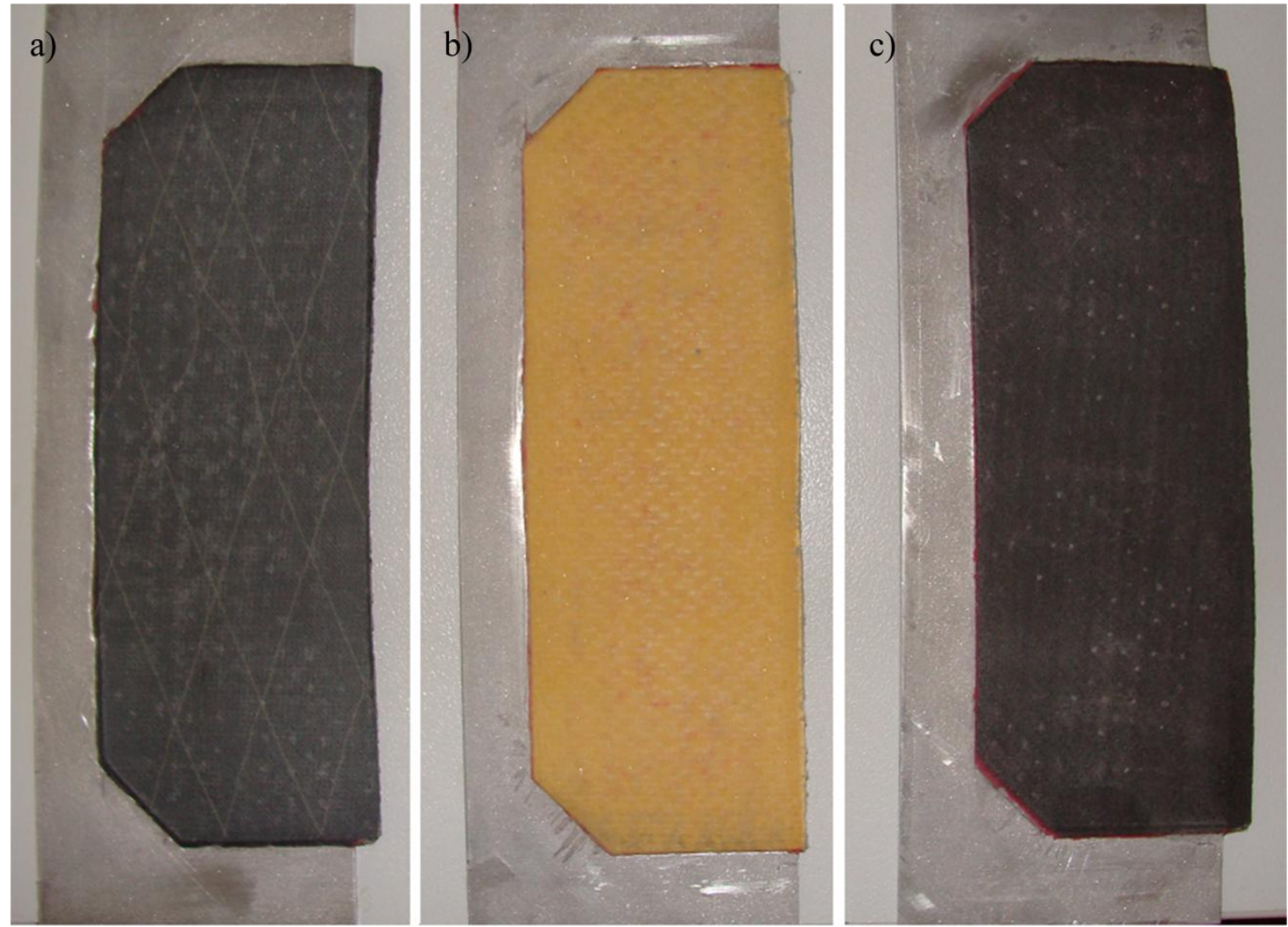

Fig. 3. The specimens after CBR: a) specimen repaired by CFRP patch, b) specimen repaired by ARFRP patch, c) specimen repaired by BFRP patch

Crack growth tests of the metal structure

The NDT investigations are performed periodically and in specified intervals. Each time a record of the structure's technical condition is taken $[4,5,8]$.

In this research notches of various length served as a model of a growing crack. The test results were compared, and the suitability of different non-destructive methods for the examination of CBR was evaluated.

Based on the experiences of researchers in the field of ABDR [5], the Eddy current method was chosen, since it enables the monitoring of crack propagation in the metallic structure under the patch.

\section{Eddy current method (ET)}

The ET method is used for the assessment of the metal structure's condition, the detection of flaws and cracks, as well as for the examination of metallic structures under composite patches.

The ET investigation was performed with the use of a MAUS V system and with a MOI device. The authors conducted a series of tests with different test frequencies. These frequencies were chosen by way of earlier research. The results indicated that the frequency of $10 \mathrm{kHz}$ gives the clearest image of damage for all types of composite patches, equally for the MAUS system and for the MOI. The best visualization, regardless of the patch's material, was obtained with MAUS system's C-scan imaging (fig. 4), even for the smallest crack (2mm model). 
a)

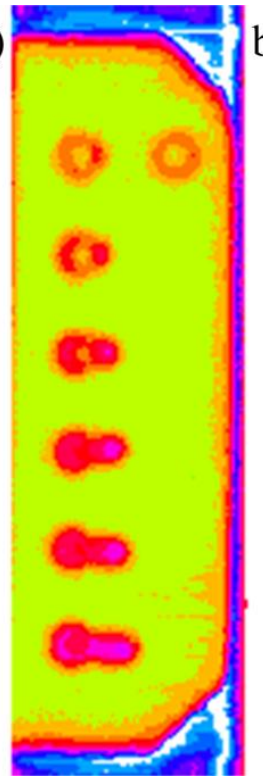

b)

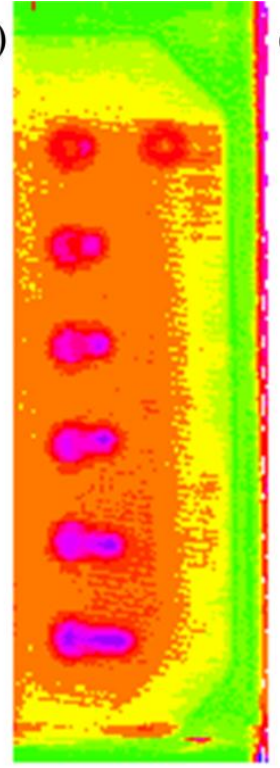

c)

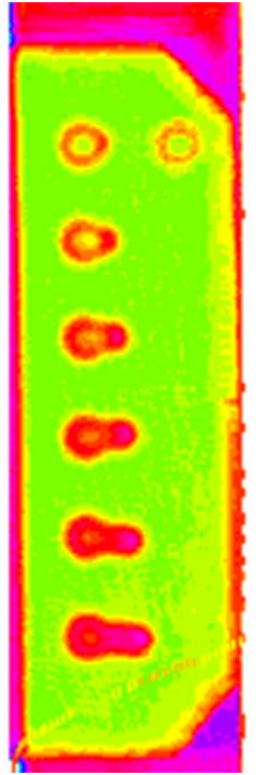

Fig. 4. MAUS's C-scan: a) specimen repaired by CFRP patch, b) specimen repaired by ARFRP patch, c) specimen repaired by BFRP patch

The automated MAUS system enables the examination of flat as well as of highly curved surfaces. However, access to the tested objects is limited by large dimensions of the sensor. Because of that, the system can only be applied to larger and easily accessible areas of aircraft skin or to particular components, de-installed from the craft.

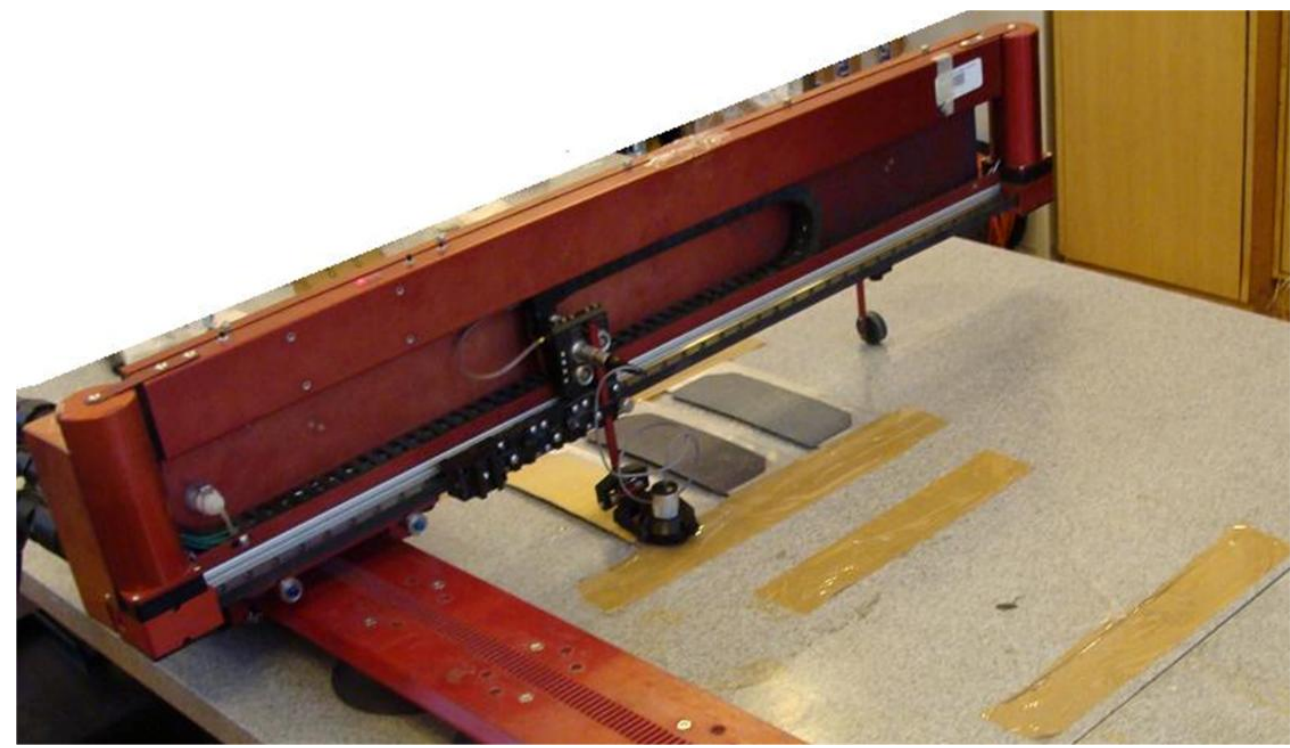

Fig. 5. MAUS V during work

Operating principle of the MOI involves the ET method, as well as the Faraday effect (magneto-optic effect), in which the polarization plane of linearly polarized light ray is rotated by a certain angle while propagating through a medium in which magnetic field is present [11]. 


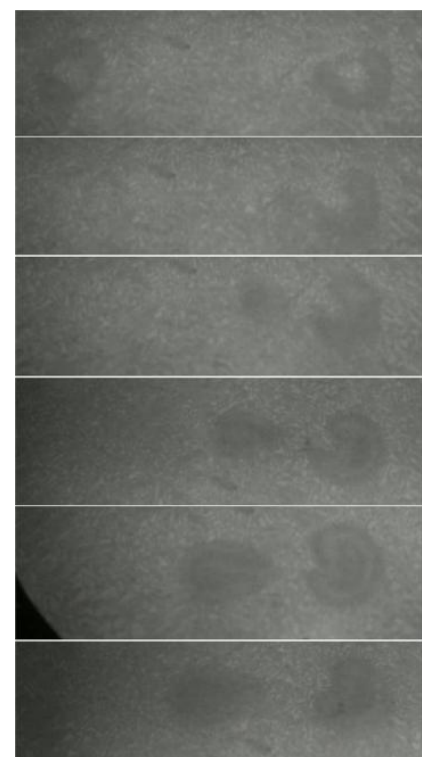

Fig. 6. Test results for the specimen repaired with the BFRP patch

For the MOI system, the resulting images' clarity and definition vary with the patch material. The best results were obtained for the BFRP specimens.
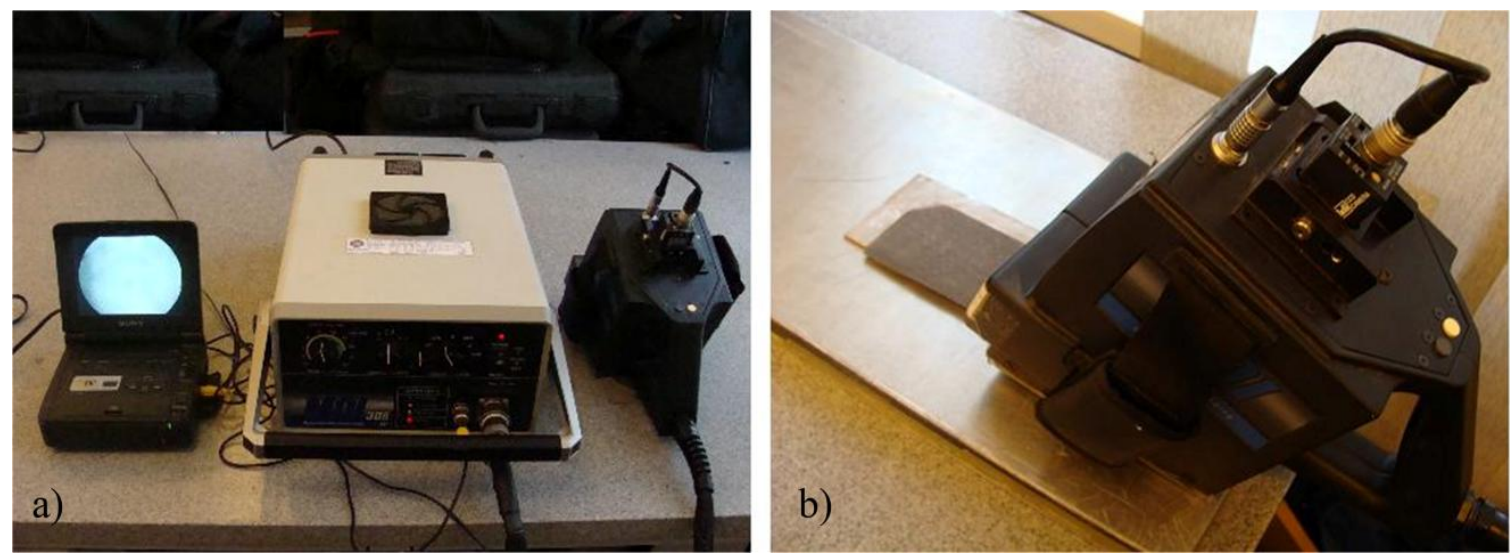

Fig. 7. MOI system: a) control unit, sensor, video recorder, b) sensor during work

One of the advantages of the MOI device is the capability to record and also to monitor in realtime the structure's condition. This property may be used for on-line observation of the crack propagation during a fatigue test.

Disadvantages of the MOI are the limited access to the examined object due to the sensor's large size, as well as the fact that the system's sensor must remain in contact with the surface inspected - therefore the object's surface should be flat or of low curvature.

The MOI system is not capable of measuring the crack length.

\section{Application of Piezoelectric sensors (PZT) for CBR monitoring}

The use of PZT sensors is a modern approach in the field of structural monitoring. Some initial research on the application of such sensors for the monitoring of composite patch covered metal structures had been carried out at the IWTL. For this purpose, the commercially-available Accelent instrumentation system was used. The system includes the PZT sensor suite and a central unit containing an impulse generator and a measurement card. The system is controlled by PC-installed software. 

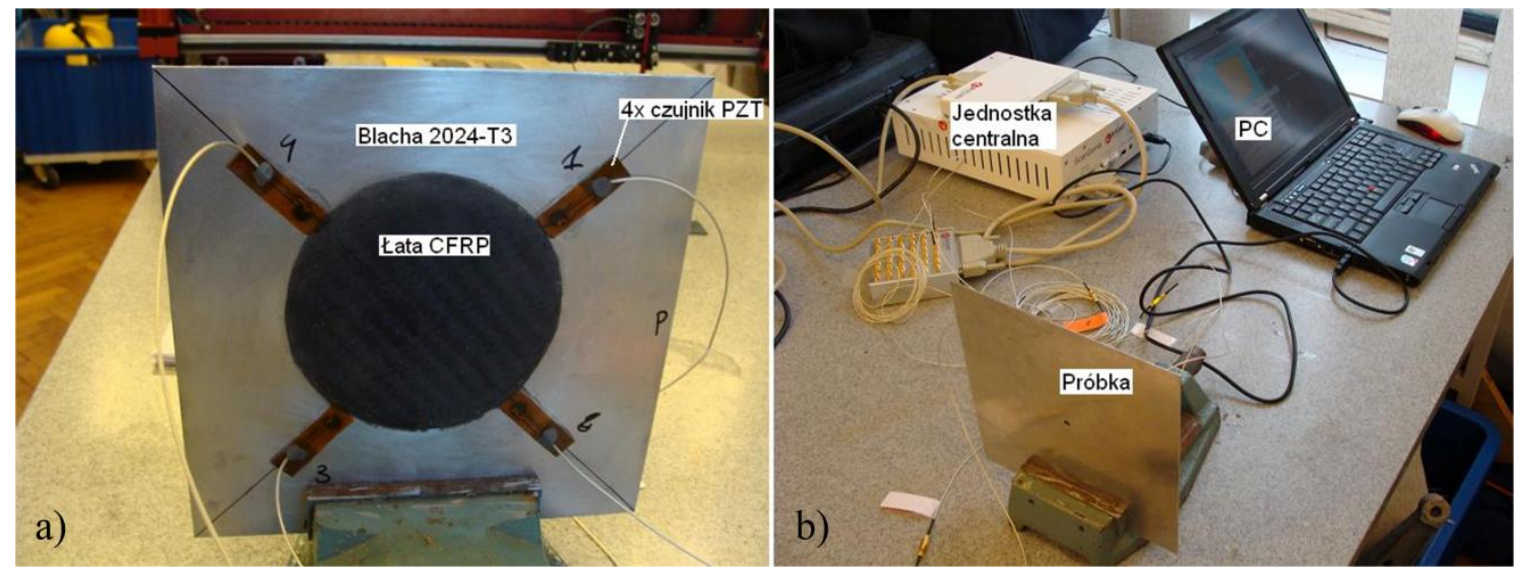

Fig. 8. The test system: a) specimens with PZT, b) Accelent equipmnet

The Accelent system's principle of operation is rooted in the Structural health monitoring philosophy, i.e.: the baseline (nominal) condition of the structure is captured and compared to any subsequent tests made after a specified period of operation.

The sensors' location coordinates are input into the software and the baseline condition of the structure is captured by registering the structure's response to an impulse generated by each of the PZT units.

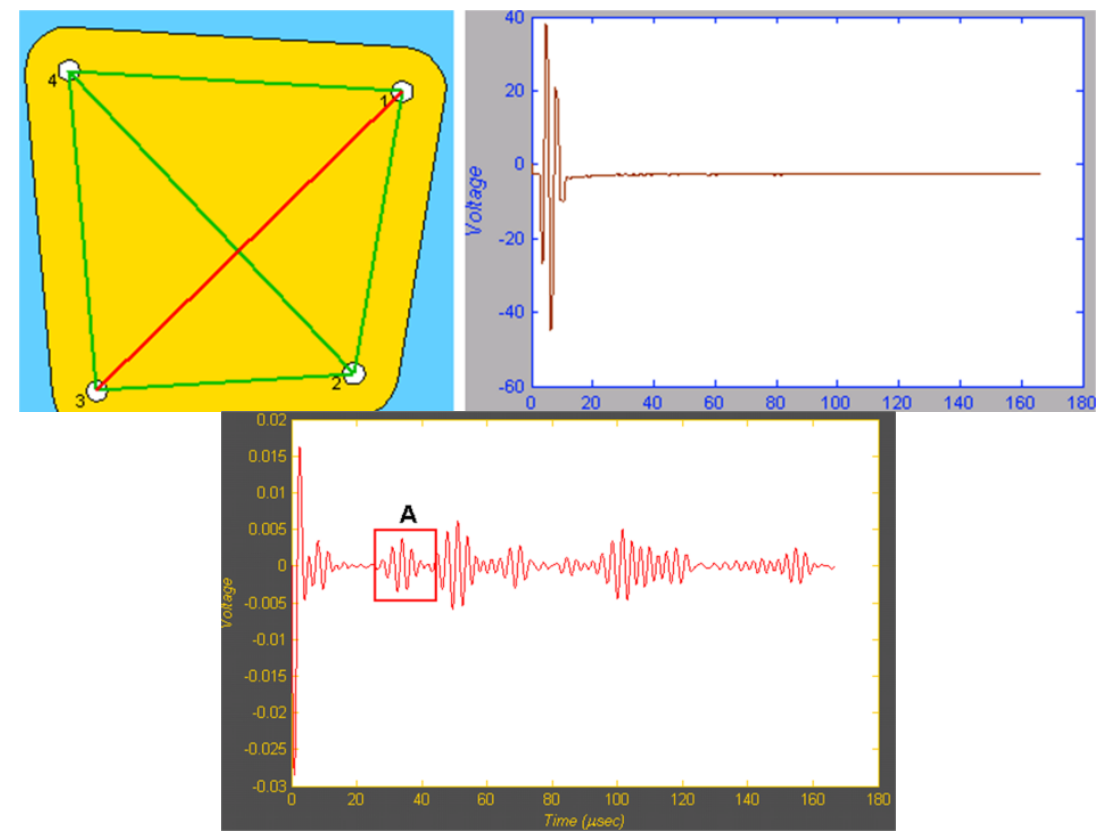

Fig. 9. Baseline: a) sensor locations, b) signal generated (300 $\mathrm{kHz})$, c) baseline structure response

The PZTs serve both as sensors and generators. In this research a three-peak sine-burst signal has been used. The software, by taking into account the recorded baseline result, the sensors' coordinates, and the form of the crack, computes the crack's location. The baseline structure used for the PZT research had the form of a $6 \mathrm{~mm}$ diameter hole. The $1.3 \mathrm{~mm}, 5 \mathrm{~mm}, 10 \mathrm{~mm}, 15$ and $20 \mathrm{~mm}$ incisions (crack models) were used in the series of tests.

The recorded response signal is used for evaluating the crack's influence on amplitude loss and phase shift (when compared to signal responses of the baseline). The occurring phase shift may be explained by the increase of the shortest wave path between the generating and receiving unit (sensor). The increase occurs because of the interaction between the crack and the generated wave. This interaction leads to a deflection of the wave. 
Table 1. The crack propagation assessment with the use of PZT sensors and Accelent equipment; green - recorded baseline signal, red - response signal of specimens with modeled damage

\begin{tabular}{|c|l|l|l|l|l|}
\hline mm & $\begin{array}{l}\text { Structure } \\
\text { condition }\end{array}$ & $\begin{array}{l}\text { Suitable, window A } \\
\text { (FIGURE 9c) } \\
\text { Transition 1-3 }\end{array}$ & $\begin{array}{l}\text { FFT } \\
\text { Transition 1-3 }\end{array}$ & Visualization \\
\hline 0 & & & & & \\
\hline 1.3 & & & & & \\
\hline 5 & & & & & \\
\hline
\end{tabular}

The diagrams show that the signal's measured electrical parameters and the crack length are related.
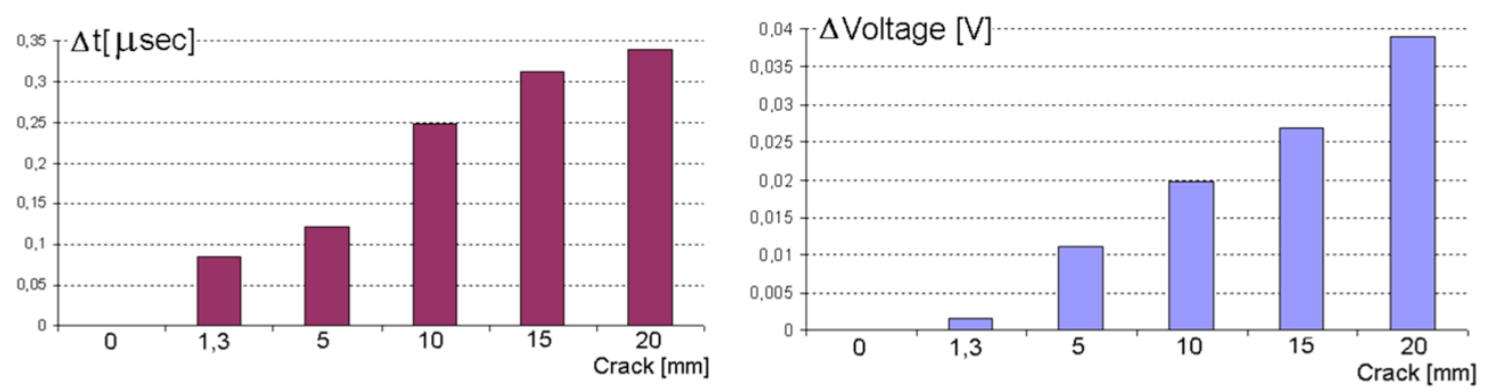

Fig. 10. Researches results: a)time delay (phase shift), b) amplitude loss 
Both in the military as well as in the civil aviation, Composite Bonded Repair is used to repair metal airframes. Boron and carbon fibers in an epoxy matrix are used as patch materials. The bond, as well as the patch and the underlying metal structure have to be monitored after the repair.

\section{Conclusions}

- The damage tolerance philosophy has an influence on the development of NDT and SHM.

- Development in the field of aircraft structure monitoring is directly linked to the development in CBR.

- Extensive CBRs have been carried out on aircraft since the 1960s. The AFIT have been involved in research in the field of CBR for the last 3 years, with the focus on matching the damage propagation with the condition monitoring results.

- The prepreg technology enables manufacturing of homogenous composite structures, which in turn makes the use of UT inspection for patch monitoring possible.

- The ET method can be employed for the inspection of repaired metal structures. The use of experimentally chosen $10 \mathrm{kHz}$ eddy current frequency filters out only the interesting response signal in metal alloys.

- The C-scan visualization system gives the possibility of registering and viewing/displaying results in real-time.

- PZT and Accelent systems can be used for real time monitoring by way of comparing the on-line/current results to the baseline structure.

- Presented NDT and PZT systems may be used during aircraft maintenance and operation, as well as in full scale fatigue tests.

\section{REFERENCES}

[1] Sałaciński M., Synaszko P., Kornas Ł. (2010). Periodyczne Monitorowanie Metalowej Struktury Samolotu Po Wykonanej Naprawie Metodą Composit Bonded Repair, Krajowa Konferencja Badań Nieniszczących, Szczyrk, 2010.

[2] Baker, A., Chester, R. \& Mazza, J. (2003). Bonded Repair Technology for Aging Aircraft. Ageing Mechanisms and Control. Specialists' Meeting on Life Management Techniques for Ageing Air Vehicles. [Technical Report, RT=-MP-079(II)]

[3] Baker, A., Rose, F. \& Jones, R. (2002). Advances is the Bonded Composite Repair of Metallic Aircraft Structure, Vol.1, Victoria, Australia.

[4] U.S. Department of Transportation Federal Aviation Administration. (2003). Guidelines for the Development of Process Specifications, Instructions, and Controls for the Fabrication of Fiber-Reinforced Polymer Composites. Office of Aviation Research Washington. (DOT/FAA/AR-02/110)

[5] Baker, A., Rose, F. \& Jones, R. (2002). Advances is the Bonded Composite Repair of Metallic Aircraft Structure, Vol.2, Victoria, Australia,

[6] Růžička M. , Kulíšek V., Henzl P., Krimbalis P., Dvořák M., Běhal J. (2007). Health Monitoring Of Composite Repairs Of Aircraft Structures, NDT for Safety, November 07-09, 2007, Czech Republic, Prague.

[7] Baker, A. (2006). Structural Health Monitoring of a Bonded Composite Patch Repair on a Fatigue-Cracked F-111C Wing., Victoria, Australia: Air Vehicles Division. (DSTO-RR0335)

[8] Dolce, F. (2010). Role of NDI in ABDR Assesment, Equipment \& Logistics. Conference Battle Damage Repair Techniques and Procedure on Air Vehicles, Prague - Czech Republic, Kosice - Slovak, Warsaw - Poland, 2010. 
[9] Lewitowicz, J., Loroch, L., Manerowski, J. (2006). Problemy badań i eksploatacji techniki lotniczej, Tom 6. Warszawa: Wydawnictwo ITWL.

[10] Dragan, K., Synaszko, P., Sałaciński, M., Klimaszewski, S. (2010). Damage Detection And Failure Mode Distribution For The MiG-29 Vertical Stabilizer. Conference Aircraft Airworthnees and Sustainment, Austin, Texsas, 2010.

[11] PRI Research and Development Corp. (2001). MOI Magneto/Optic Eddy Current Imager. Operator's Manual, Torrance, USA.

[12] Uhl, T., Ostachowicz, W., Holnicki-Szulc, J. (2008). Structural Health Monitoring, Poland. 